CATALAN REVIEW

Catalan Review

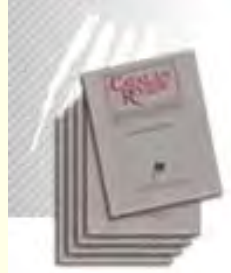

You are accessing the Digital Archive of the Catalan Review Journal.

By accessing and/or using this Digital Archive, you accept and agree to abide by the Terms and Conditions of Use available at http://www.nacs-

catalanstudies.org/catalan_review.html

Catalan Review is the premier international scholarly journal devoted to all aspects of Catalan culture. By Catalan culture is understood all manifestations of intellectual and artistic life produced in the Catalan language or in the geographical areas where Catalan is spoken. Catalan Review has been in publication since 1986 .
NORTH

AMERICAN

CATALAN

SOCIETY
Esteu accedint a l'Arxiu Digital del Catalan Review

A l' accedir i / o utilitzar aquest Arxiu Digital, vostè accepta i es compromet a complir els termes i condicions d'ús disponibles a http://www.nacs-

catalanstudies.org/catalan_review.html

Catalan Review és la primera revista internacional dedicada a tots els aspectes de la cultura catalana. Per la cultura catalana s'entén totes les manifestacions de la vida intel lectual i artística produïda en llengua catalana o en les zones geogràfiques on es parla català. Catalan Review es publica des de 1986.

\title{
Quatre modalitats en la poesia de Josep Carner J.N. Santaeulàlia
}

Catalan Review, Vol. VI, number 1-2 (1992), p. 325-369 


\section{QUATRE MODALITATS \\ EN LA POESIA DE JOSEP CARNER}

(Entorn dels poemes inèdits

i els no publicats en llibre inclosos a Poesia)

\section{J.N. SANTAEULÀLIA}

És una opinió avui compartida per molts crítics i literats d'aquest país que Poesia, de Josep Carner, constitueix el cim més alt de la poesia catalana moderna.' Aquesta valoració contrasta $\mathrm{amb}$ la indiferència amb què l'obra va ser rebuda l'any 1957. ${ }^{2}$ Eren, certament, uns altres temps i unes altres circumstàncies; però això no ens priva de sorprendre'ns, des de la perspectiva actual, de la miopia de la crítica - o com vulguem dir-ne-d'aleshores. O tal vegada, en lloc de miopia, hauríem de parlar de sorda hostilitat i mala fe: no hem d'oblidar que Poesia apareixia després d'un polèmic procés de revisió dels poemes-i-selecció i dispersió en un nou conjunt-, que havia estat envoltat, en paraules de Jaume Coll, ${ }^{3}$ d'una «franca i patent atmosfera de dissensió general».

Fos com fos, la polèmica sobre la revisió i l'agrupació temàtica dels poemes no tan sols va impedir en el seu moment una valoració justa de Poesia, sinó que, de retop, va relegar al sílenci el centenar de poemes inèdits que Carner hi donava a la llum, als quals cal sumar els 44 poemes que

\footnotetext{
' Alguns van encara més enllà. Així, Narcís Comadira considera el volum de 1957 com a "clau de volta de tota la literatura catalana moderna". Aquesta afirmació es troba en un interessantíssim article publicat a La Vanguardia el 9 de febrer de 1984 , titulat "La pedra de tocm.

${ }^{2}$ La publicació de Poesia "no va produir cap efecté seriós enlloc», afirma Joan Ferraté a "Poesia, de Josep Carner: Ressenya i vindicación, Els Marges, n." 8 (setembre de 1976), pàg. 15 .

3 "Introducció» a Poesia, Barcelona, Quaderns Crema, 1992, pàg. XxxviI.
} 
fins llavors només havien estat publicats en diaris i revistes. ${ }^{4}$

El present treball té com a objectiu l'estudi d'aquest corpus, que aplega peces d'una extraordinària qualitat i del qual es pot dir que constitueix, amb Nabí i la cinquantena d'inèdits de Paliers, Llunyania i Arbres, la culminació de la fecunda trajectòria poètica de Josep Carner. Els inèdits del 57 són, a més, un singular exemple d'un dels aspectes essencials de la seva poesia: la prodigiosa $\mathrm{i}$ incomparable varietat de registres, temes, modalitats i formes que hi conviuen.

Ja en una data tan reculada com I9I4 Carles Riba apuntava aquest tret a propòsit de La paraula en el vent. "Cada aplec-escrivia - al costat dels altres aplecs, i cada poema al costat dels altres poemes dins un mateix recull, diria que apareixen una mica a la manera de manifestacions disperses i fins a cert punt estranyes entre elles, jassia que totes convergeixen a lligar-se per invisibles fils a una idea central que les governa i vigoritza i penetra».' Davant això, diu Riba, «ens angunia tot d'una com un curiós daler d'unificació, aparentment insatisfeta». Aquesta angúnia unificadora, tan pròpia d'un crític com Riba, es manifestava davant la poesia carneriana de l'estadi noucentista, quan el ventall de la seva diversitat només $s$ 'havia començat a obrir, quan encara no havia escrit $L$ 'oreig entre les canyes, El cor quiet, El veire encantat, Nabi, Llunyania..., obres en què el desplegament-no pas la dispersió-de veus, tonalitat i figuracions seria encara molt més ampli. Estudis i aproximacions més recents han tornat a incidir sobre aquest tret de l'escriptura carneriana, "proteica" $i$ «camaleònica», d'una «infinita gamma de registres»-els termes

4 La majoria d'aquests poemes foren escrits durant les dècades dels 40 i 50 , per bé que alguns són anteriors. Jaume Coll, a l'esmentada "Introducción, reprodueix una carta del poeta a Marià Manent, dacada l'any 1954, en la qual es refereix a "qualque lavorino assai recente» com a complement dels poemes seleccionats i revisats que havien de ser publicats a Pocsia. Hem d'entendre que alludeix als poemes que estem estudiant.

" "La paraula en el vent, al marge d'un llibre de Josep Carner", Obres Completes, 3 (Critica, 2), Barcelona, Ed. 62, pàg. Is. 
són, respectivament, de Narcís Comadira, Salvador Oliva i Joan Fuster. Les obres de Carner, salvades poques excepcions, fan la sensació de reculls de material heterogeni on cada poema, en comptes d'imbricar-se en un conjunt ordenat, s'erigeix en un món absolut per ell mateix, dins una clara i profunda unitat d'escriptura. Carner és, podríem dir, poeta de poemes, més que de reculls unitaris. Potser per això mateix va poder reordenar la seva obra tal com ho va fer, barrejant el material en noves seccions temàtiques i suprimint la majoria de títols dels antics i provisionals reculls-cosa inconcebible, per exemple, en les obres de Riba, Foix o Espriu, tan compartimentades en blocs unitaris dins els quals cada element sembla tenir una funció arquitectural.

Acceptada la diversitat com a valor consubstancial i singularitzador de la poesia de Carner, com a manifestació de la seva extraordinària energia creativa $\mathrm{i}$ també com a fruit de la "grandíssima» amplada del "compàs de la seva curiositat» -en mots de Josep $\mathrm{Pla}-{ }^{6}$ podem dir que cap recull ofereix una mostra tan rica de la versàtil fecunditat de Josep Carner com el conjunt dels inèdits de 1957. Es lògic que sigui així, tenint en compte que la seva trajectòria, més que passar per estadis evolutius, es caracteritza per desplegar-se en noves línies sense renunciar a les anteriors - com ho prova el fet de la persistència de la més pura vena noucentista fins als seus darrers poemes. Seria inexacte, doncs, afirmar que el Carner arbitrari deixa pas al simbolista, i aquest, després de la guerra, a un Carner humanitzat $\mathrm{i}$ adolorit. Carner no elimina, sinó que va incorporant $i$ acumulant influències, temàtiques, modalitats, registres... I és en l'estadi culminant de la seva maduresa on conflueixen totes aquestes línies. Heus aquí un dels valors més remarcables d'aquest conjunt de poemes, si l'agafem com a tal conjunt: el de constituir

6 " Josep Carner. Un retratw, Homenots (Tercera sèrie), Obra completa, $2 \mathrm{f}$. Barcelona, Ed. Destino, 1972, pàg. 245. 
una mena de radiant síntesi de tota la producció carneriana.

Tanmateix, a l'hora d'assajar-ne una anàlisi, o tan sols una aproximació crítica, ¿com ens podem orientar pel laberint d'aquesta massa de poemes tan diversos? Dividir els poemes segons el tema o la forma no portaria enlloc. Cal buscar analogies més profundes entre els poemes per tal de trobar les línies bàsiques en què fonamentar l'anàlisi.

Hem cregut que la solució més operativa consistia a ordenar els poemes seguint el que en podríem dir la modalitat predominant en cada un. En el nostre cas, aquestes modalitats podrien, a grans trets, reduir-se a quatre: arbitrària, civil, simbòlica i introspectiva. Serien, per dir-ho d'alguna manera, les quatre artèries principals per on flueix la poesia carneriana.

\section{I. «LA VIDA COM A ESPECTACLE»?}

La modalitat arbitrària es troba en aquells poemes en què el tema és la realitat externa, el món com a espectacle-el paisatge, els objectes, la gent, els mites-, sense interposició explícita del jo dins la ficció lírica, si no és com a simple espectador passiu, gairebé una figura ornamental. Aquesta modalitat predomina-gairebé en exclusiva-en l'etapa noucentista de Carner (fins pels volts de 1920), i és abundant en la seva producció posterior. També la podríem anomenar figurativa, aplicant-li el qualificatiu emprat en art per designar, en oposició al d'abstracte, els corrents que representen realitats externes $\mathrm{i}$ concretes.

Aquesta parcella de la poesia carneriana és la més coneguda i estudiada, i d'aquí en va sortir la «imatge tòpica» que ben aviat es va difondre de l'obra del "príncep dels poetes»:

7 Aquest títol és extret del pròleg a la segona edició de Els fruits saborosos (1928), on el poeta es reconeixia «un enllaminit de la vida com a espectable i de P'idioma com a exercici d'entretocs». 
una poesia com a joc verbal que, partint del pretext d'un simple element paisatgístic o una anècdota qualsevol, de vegades tan sols d'un detall minúscul, desplegava tot d'insospitades figuracions, sense que mai els conflictes interns del jo apareguessin en primer terme, com si el pudor, la reserva o l'escut de la ironia mantinguessin el poeta projectat només enfora, convertit en pura energia verbal capaç de transfigurar màgicament tot allò que tocava.

La modalitat arbitrària o figurativa, ja ho hem dit, és també present en el conjunt de poemes que estem estudiant. En alguns casos, com si els anys no haguessin passat, retrobem encara el Carner més típicament noucentista, el poeta de la llum i de la pura joia, de la "contemplació meravellada" i la *tendra mirada" sobre les coses-les expressions són de Marià Manent-, però que sempre manté el to contingut de qui es vol distant, no pas confós, en relació al paisatge descrit.

$\mathrm{El}$ poema "Canvi» en seria un bon exemple:

La pluja cau amb un goig de gatzara

i de biaix corre el sol entremig;

una pomera, de flors tota clara,

pensa que és d'or cada esquitx.

Els elements barrejaren llurs tresques

i l'un amb l'altre, saltant, es confon;

corren, s'empaiten; amb crits i juguesques

rejoveneixen el món.

És l'ún mortal consirós, l'altre canta.-

Mentre, a ple sol, ve un ocell a fer niu, sobre un esbart que recula i s'espanta

hi ha un núyol negre que riu.

En escriure aquests versos, Carner semblava encara tenir ben present, malgrat el temps transcorregut, el decàleg que, en forma de glosa, Eugeni d'Ors adreçava als artistes l'any 
1909. Deia el punt $\mathrm{I}$ : «El primer dever del paisatgista és no formar part del paisatge»; i el punt X reblava el clau: «El protagonista del paisatge és el paisatge». ${ }^{8}$ Des de l'òptica noucentista, es tractava de depurar l'art-en el nostre cas la poesia-de les impureses romàntiques, de les efusions passionals, de l'exhibicionisme sentimental. Contra això s'imposava la contenció, la mesura, el distanciament. Aquesta reacció classicista $\mathrm{i}$ anti-romàntica es traduí, en el cas singularíssim de la poesia de Carner, en una tècnica d'ocultació del jo que en podríem anomenar despersonalització o, seguint Carles Riba, objectivació. El poeta com a individu no involucra explícitament els seus sentiments en el poema; es limita a actuar com a espectador passiu $o$, com a molt, $s^{\prime}$ hi inclou com a figura decorativa, per bé que, òbviament, és ell qui, en un altre pla, absorbeix les sensacions de l'exterior i les reelabora segons la seva sensibilitat, imaginació i domini del llenguatge. El poeta, podríem dir, arbitra el poema sense entrar en el joc.

L'objectivació no equival, en la poesia arbitrària de Carner, a una fredor abstracta i exànime, a una simple representació objectiva del món, a una total deshumanització. Just al contrari: el poema és buit d'un jo subjectiu en benefici d'una vida desbordant que s'hi manifesta arreu, en tots els elements. Com assenyala Joan Ferraté, l'escriptura carneriana tendeix a l'«animació constant de les dades de l'experiència externa (...), a les quals és atribuïda la funció de personatges arreu actius en el petit o magne drama que és cada poemas." Un dels màxims valors d'aquesta poesia és la seva capacitat vivificadora. Totes les coses hi prenen vida, s'hi humanitzen constantment, pensen, parlen i es relacionen entre elles, se'ns fan vives i pròximes, entranyables.

Fixem-nos, a tall d'exemple, en l'arrencada de "Canvi». La força vital que irradia el primer quartet prové de la reite-

\footnotetext{
${ }^{8}$ Glosari (selecció). Barcelona, Ed. 62 i "La Caixa», 1982, pàg. 88.

9 "Pròleg" a La primavera al poblet, Barcelona, Ed. 62, 1979, pàg. 27.
} 
rada personificació dels elements que intervenen en l'escena: la pluja, el sol, la pomera florida. Una simple impressió visual esdevé, verbalitzada, una apoteosi de vida, llum i transfiguració. La segona estrofa reprodueix la mateixa sensació, però ara accentuant-ne, d'una banda, l'abstracció-com si la impressió inicial s'hagués traduït en una reflexió generalitzadora-i, de l'altra, el dinamisme-només cal veure l'ús que s'hi fa dels verbs. En canvi, el tercer i últim quartet, una mica més complex, ens presenta els dos elements, sol i pluja, no ja confosos, sinó separats, simbolitzant l'un l'esperança, la vida, la primavera, i l'altre alguna força obscura i sinistra-la mort, l'hivern, la desolació. Hi ha una clara antítesi entre aquests elements, com també en la reacció dels ocells: les dues cares de la realitat es fan així presents en el poema.

$\mathrm{Amb}$ aquest canvi final, el quartet, sense abandonar la tècnica objectivadora, escapa una mica al to noucentista $i$ ens mostra, com en bona part de l'obra de maduresa, un Carner més propens-potser només per raons biogràfiques-a descobrir en la natura, al costat de la joia de viure, les ombres de la desolació, la solitud i la mort. Amb tot, es tracta aquí d'«un núvol negre que riu», com si només jugués a espantar uns ocells.

El poema «Primavera prima» complementa «Canvi» en alguns aspectes. La primavera, personificada, es pregunta si el seu esforç animador paga la pena. També hi apareix un núvol que enfosqueix un moment la llum i atenua la força vital. Però finalment triomfa la primavera, i els versos es tornen a omplir d'energia:

El nûvol s'allunya i el dubte finí,

Amb lleu feixuguesa borrona el teu si.

-Foc-crides-, encén-te al roser mês gai. 
- Fes ta verda pluja

-manes al desmai.

Dels nius la cabuda

mesuren tos dits;

promets a les cuques

mil marges florits.

(vv. 29-40)

La febre vital fins s'encomana a un vell, el qual, en tombar-se cap a la seva fi, veu que la mort i la primavera són una mateixa cosa, identificació que es podria interpretar, en el context de la poesia carneriana, com la promesa d'una nova vida enllà d'aquesta. Com hem dit anteriorment, aquest toc de profunditat final, ni que sigui per la simple suggestió d'una ombra - una al-lusió a la vellesa, la mort, la solitud...-, sovinteja en els poemes de maduresa i n'és un tret distintiu, per bé que la modalitat és essencialment la mateixa que la dels poemes pròpiament noucentistes.

Tornant a la mecànica de l'objectivació, fou Carles Riba el primer a teoritzar-hi. Així, arran de La paraula en el vent (I9I4) afirmà de Carner com a poeta: «la seva peculiar col-locació enfront i entre tot allò que és pretext del seu cant dóna a la paraula d'ell una vida part defora de la d'ell mateix, i per tant indefinidament rica d'aspectes diversos. Com si ell fos sortit de dins ell mateix a la realitat exterior». ${ }^{10} \mathrm{I}$ això, diu, el relaciona "amb els més purs lírics grecs", entenent com a puresa el fet que en el poema no es barregen sensasions i sentiments, el món i el jo. Aquestes paraules són molt aclaridores, Carner, segons Riba, es projecta en la realitat exterior, que actua com un mirall. En tot cas, queda clar que la llum-i l'ombra-procedeixen del poeta, encara que això no s'expliciti en el poema, pur de qualsevol pollució sentimental, de qualsevol força egocèntrica.

10 Ibid, pàg. 16. 
Quatre anys més tard, a propòsit de Bella terra, bella gent, el mateix Riba bateja aquesta "norma carneriana" com a "objectivació». "Un poema de Carner és «un pretext líric que ricament s'amplifica", en el qual, afegeix més endavant, "l'home projecta damunt del paisatge la seva arbitrarietat». Riba hi insistirà encara en un text clau, la ressenya de "L'oreig entre les canyes" (1920). En el poemes de Carner, diu, "el pretext líric (...) gira, talment, davant els nostres ulls, com una gemma que fa valer les mil lluissors de les seves facetes (...) La necessitat de penetrar per anàlisi fins al fons, hi és desconeguda». I més endavant: "No és l'escandallament d'un món que ens turmenta amb el misteri (...) sinó la reproduïda contemplació d'un món, reflex ideal del nostre». Sense intervenir-hi, sense involucra-s'hi directament, el poeta assisteix a l'espectacle que li ofereix la natura "com un déu venturós».12 Carner és únic per "aquest do incansable d'objectivació lírica", que el $\mathrm{fa}$ - torna a remarcar-ho- ael cas més pur de lírica que s'hagi donat entre nosaltresn.

Les brillants teoritzacions de Riba han estat represes, més ençà, per Joan Ferraté. Carner, segons ell, s'aparta del «subjectivisme radical" que caracteritza l'estètica del seu temps pel camí de "l'abnegació d'ell mateix en els seus pretextos", amb la finalitat de evèncer, ultrapassant-lo en la direcció de la pura objectivació, el problema suscitat per la seva acceptació, sense reserves aparents, de la funció representativa com a motivació original del seu discurs". ${ }^{13}$ D'aquí que un bona part de l'obra carneriana, la que aquí apleguem dins la modalitat arbitrària, ignori qualsevol conflicte romàntic, esqueixament $\mathrm{o}$ xoc entre les realitats interna i externa del poeta, car en el poema només existeix aquesta última com a força activa. I si el poeta en certa manera en capta les sensacions, la reconstrueix

" «Bella terra, bella gent", Obres Completes, 2 (Critica, 1), Barcelona, Ed. 62, pàg. 102.

12 Obres completes, 2 (Critica, $t$ ), Ibid, pàgs. $207-209$.

17 *Pròleg" a La primavera al poblet, cit., pàgs. 18-19. 
i l'anima amb el seu encanteri vivificador, en cap cas no pretén convertir-la en una simple traducció o metàfora de conflictes interns, a la manera dels romàntics. Aquest és el sentit de la puresa que li atribuïa Riba: és una poesia com a pura representació.

I encara més recentment, Dolors Oller ha prosseguit en la mateixa direcció. "Naturalment", afirma de Carner, "que és la seva manera de mirar l'objecte i formalitzar-lo allò que ens el fa interessant, però aconsegueix que, atorgant-li vida pròpia, oblidem l'existència d'un jo-autor per acarar-nos a un jo líric que s'expandeix als propis pretextos $\mathrm{i}$ al mateix lector». ${ }^{14}$

D'entre els inèdits del 57 , poemes com $« \mathrm{Fi}$ de maig a la campina» $\mathrm{o}$ «El foc $\mathrm{i}$ les roses* són comparables, quant a la tècnica objectivadora, als dos que hem esmentat, $\mathrm{i}$ igualment representatius de la pervivència del primer Carner en la producció posterior: tots transmeten, d'una manera o altra, un impuls vital que sembla animar-ho tot i que té quelcom de força còsmica, expressada en uns versos «sense altra finalitat que llur mateixa perfecció somrient", en afortunada frase de Carles Riba.

No obstant això, una bona part dels poemes de la modalitat arbitrăria, d'entre els inèdits de 1957 , presenten una evident inflexió de to en relació al més típicament noucentista; així, la "contemplació meravellada" deixa lloc a una mirada més greu sobre l'espectacle del món, sovint convertit en un escenari de desolació. Això es comença a veure en poemes com «Adéus», "Mar i cel», "Tardor a Bruges», "Tots Sants», "Entrada d'hivern», "Fred matinal»..., els quals, d'altra ban$\mathrm{da}$, són també representatius de la insistència del Carner madur a reproduir ambients de tardor i d'hivern, desproveïts d'impuls vital, paisatges inànimes i espectrals. Un exemple extrem d'aquesta escenografia de la desolació el tindríem en el

14 "Josep Carner: de la llei i de la gràcian, dins E. Bou et al., Josep Carner; llengua, prosa, poesia. Barcelona, Ed. Empúries, 1985 , pàg. 107. 
poema «Sota una boira de tardor», escrit a Beirut a finals d'estiu del 36 i no publicat en llibre fins Poesia.

Res del vivent no canta ni somica; glops de no res ens vénen a colgar; sembla que Déu son vell dibuix critica i que es repensarà.

No deu glatir cap fulla ni cap ala. Només, la sola d'un gran cor antic, en l'últim pi que es veu, una cigala fa un sol i vern xerric,

igual que el ballador que dansa encara quan ja cessà del ball l'últim acord, com l'artiller fanàtic, que dispara quan ja tothom és mort.

Carner, que ha transmès tanta vida en els seus versos-fins i tot en aquells poemes noucentistes ambientats també en la tardor i l'hivern-, sembla recrear-se aquí en l'espectacle de la mort. Els versos I is, que delimiten la primera part del poema, són especialment remarcables per les partícules negatives que precedeixen tots els termes que podrien tenir connotacions vitals: "vivent", "canta", "somica», "somica»; "glatir", "fulla», "ala». I, entre aquests dos versos, una figuració reiterada en la poesia de maduresa de Carner: la boira com a element d'anihilació - ni que sigui temporal-de la realitat. La segona part del poema (del vers 6 fins al final) es centra en la figura de cigala, l'única criatura viva que es resisteix a desaparèixer, que encara s'obstina a viure-i tanmateix condemnada a ser engolida, tard o d'hora, pel no-res. El poema, encetat amb el mot «res», es clou amb el de «mort», després de dues comparacions, al tercer quartet, que accentuen encara el to desolat del conjunt.

El poema «La lluna cantava» ens ofereix una altra versió 
del mateix tema. De fet es tracta d'un cant a la mort posat en boca de la lluna, que s'adreça als vivents i els incita a descobrir els seus "béns", descrits en una successió d'imatges enigmàtiques i suggestives:
Al fons pàl-lid d'una gorga
hi ha els joiells més resplendents;
faig del bosc pintat de gebre
el palau de més esclat;
dóna el bes que més enfebra
un fantasma recordat;
canten serps enamorades
en un cingle inconegut;
sense testa, les onades
tenen cuixes de vellut;
més secrets la boira cela
que el vell seny dels immortals;
el vaixell que fa més vela
és un núvol sense pals.

(Vv, II-24)

Aviat descobrim que aquest regne màgic, transformat per la illuminació lunar, no és sinó el símbol de la mort i el no-res. I el poema es clou amb l'aparició de la figura sinistra del negat, és a dir, d'aquell que ha cedit a la seducció del cant de la lluna, que no és sinó una invitació a morir.
Ah, si amb nines expandides
em copséssiu fit a fit!
Us daria noves vides
l'encanteri de l'oblit.
El meu cant ramells us porta
del no-tes i de l'enlloc.
Bella só perquè só morta
d'aquest gel que encara és foc.
I si dormen tots a vila,
veig un cap mirant, mirant: 
a flor d'aigua ja s'enfila

un negat capcinejant.

$$
\text { (vv. } 25-36 \text { ) }
$$

Altres poemes, a més d'incorporar el to de la desolació, s'aparten lleugerament de la modalitat arbitrària, en el sentit que l'objectivació ja no hi és total, sinó que s'obren excletxes a la penetració del jo, i una aura de subjectivisme comença a entelar la representació objectiva del món. Això succeeix en poemes com «Vent en proa», «Record d'un núvol» $\mathrm{i}$ «Plany de febrer", un altre poema hivernal que reproduirem sencer:

Hi ha enmig del cel hostil la flor malalta (el sol no sap encara d'escalfar).

Les ombres dels qui passen són tan primes que un hom comença a creure que se'n va.

¿On fugirem que retrobem la petja del cant desfet i de l'amor perdut? ¿On fugirem que no ens rebutgi l'aire i que la llum del sol tingui virtut?

Perquè encara s'ajupen les teulades, és rígida la roba dels terrats, $i$ ens fan l'ull trist els vidres de les cases $i$ jeuen els camins descorarjats.

La «desanimació» és tan sistemàtica aquí com a «Sota una boira de tardor»: el sol apareix com una «flor malalta» en un cel «hostil», i hom pressent l'amenaça de l'anihilació; les teulades «s'ajupen", les finestres fan "l'ull trist", i els camins "jeuen» «descoratjats». La tècnica d'aplicar la proposopeia sobre substantius referents a elements del paisatge és la mateixa que en els poemes de to vital, però aquí ja no es transmet la sensació de vida, sinó just el contrari.

Quant a l'accentuació del subjectivisme, només cal llegir 
el segon quartet, encara que el jo s'hi trobi expressat (o disfressat) en primera persona del plural. El "paisatge interior" desplaça l'exterior, i el to elegíac es fa més evident. Ens trobem, gairebé, en una altra dimensió poètica, o almenys en una línia divisòria de transició cap a una nova modalitat: la que anomenarem introspectiva, que veurem més endavant.

Com una mena d'apèndix a l'estudi de la modalitat arbitrària, acabarem parlant dels poemes que, en comptes de descriure un paisatge, agafen com a pretext la figura humana, l'anècdota, el mite. Aquests poemes, amb algunes variacions de caire tècnic (la narració preval sobre la descripció, per exemple) ens mostren també un Carner abocat enfora, objectivador, i és per això que els hem inclòs dins la present modalitat. La majoria dels que trobem entre els inèdits de Poesia es poden situar dins una línia de continuïtat noucentista, per bé que també hi apareixen motius, temes i tonalitats més pròpies de la tardania.

Per començar, entrarien dins aquest grup els poemes de circumstàncies ( $\mathrm{A}$ Feliu Elies, convalescent», "A una enamorada", "Cançó d'un nom», el bell poema "A Francina» -aquest últim, però, amb una punta d'enyor i de recança que el fa més «humanitzat»). I també alguns poemets que s'inscriuen en la línia de la tipologia carneriana noucentista, allò que Riba anomenà "la comedieta humana». En són exemples "Cuina» $\mathrm{i}$ «El captaire».

També hi podríem incloure els poemes centrats en figures femenines, o amb presència de l'element femení. Situats igualment en la tradició noucentista, més que poemes amorosos són poemes galants ("galanies», com en deia el mateix Carner). L'amor hi és com a tema, com a exercici retòric, com a joc que s'organitza a partir de situacions arquetípiques $\mathrm{i}$ amb un jo (quan hi apareix) que té tot l'aire d'una figura impostada, sense cap vibració d'autenticitat. Entrarien dins aquest subgrup els poemes "A una enamorada», "Cançó del dece- 
but», «Joc d'opostos» o "Cel cobert». Vegem, per posar un exemple, aquest últim, de només quatre versos:

El sol, enquimerat amb cada cosa, amagà tot avui sa festa d'or.

Sols perquè penso en vós, el dia mor entre una glassa de color de rosa.

Un altre grup, més nombrós, seria el format pels poemes o balades de caire narratiu. Molts tenen com a tema o rerafons el mar: «El savi»-quasi una rondalla, muntada sobre una facècia-, "Ariel i els peixos»-petita faula amb ingredients mitològics-, "Cançó de la flor massissa» $\mathrm{i}$ «Els ports i la mar»-cançons de mariner-, «Comiat», «El galiot i la sirena», «Mariner sentimental», «Un mariner, vilatà d'un dia»... En aquests poemes hi trobem un altre dels ingredients bàsics del Carner noucentista: l'humor, la ironia sempre amable, amb un toc de tendresa. El mar, en general, hi apareix com a símbol de la llibertat, el canvi constant, l'imprevisible (en constrast amb la terra, el port, la vila rutinària). Dóna la sensació que en molts d'aquests poemes Carner vol esplaiar indirectament la seva vena viatgera $i$ aventurera.

La virtut alliberadora del mar és expressada, ara sense humor, amb un to més greu, en el poema «Suïcidi», on el mar (¿o la lluna?) increpa un cadàver-torna a sortir la figura del negat-per no haver-s'hi lliurat abans, quan encara vivia:

Una nit de lluna sense cap vivent

ni barca, ni núvol, ni vent, un finat flotava, rastre indiferent, i una veu li deia com en un lament:

-Oh pàl-lid covard!

¿Per què no vingueres abans? Ara és tard.

Al mês decebut 
els deserts de l'aigua donen la salut, la rosa dels vents retorna el delit; i tu, reforçat en seny i sentit, i dreçat de sobte per nova virtut, amb una tempesta t'hauries batut $i$ hauries servit.

La veu de la desolació, que ja hem trobat abans, s'insinua també en poemes com són "Diumenge del patró», "El vell $\mathrm{i}$ la nau» $\mathrm{i}$ "Guerra".

Una altra colla de poemes narratius tenen com a elements comuns figures i passatges de l'Antic Testament. És el cas de "Cants de Caïm i d'Abel», "L'esperitat", "L'Eternal i el temple» $\mathrm{i}$ «Si us plau». En aquest últim poema, un vell, solitari en sa cabana, víctima de la solitud i el desconhort, és cridat a morir. Quan es posa en camí per afrontar el seu destí, una merla li anuncia amb el seu cant l'alliberament i la joia del més enllà. En aquest poema no hi intervé el jo del poeta, però hom hi endevina el mateix sentiment religiós que Carner expressà en diversos poemes de maduresa de manera molt més personal, abandonant la modalitat figurativa i els correlats mítics.

Per acabar, una bona mostra de com Carner alterna el to més lleuger de la primera època amb la reflexió greu i profunda, el joc i la ironia amb la desolació, la trobaríem en els tres poemets nous que s'incorporen, a Poesia, secció AUQUES I VENTALLS, a la tan noucentista «Tirallonga dels sisos i els asos d'aquest món». Dos dels apariats concorden perfectament amb el to dels primitius: «Un noi que promet» $\mathrm{i}$ «El censor, a un astrònom que li porta un text». Però el tercer només podia ser escrit pel Carner de maduresa, el que ha passat per les experiències de la guerra, l'allunyament, l'envelliment i l'acuit de la mort. Es titula «Un vencedor, passat un segle», i és d'una concisió lapidària, d'una densitat esborronadora:

Tres ossos encauats, lluny dels matins, i una urpa sola amb el no-res a dins. 
Poques vegades s'haurà expressat amb un laconisme tan extrem la futilitat de la glòria i del poder, l'espoli total de la mort, la fragilitat essencial de qualsevol victòria: amb el temps, sempre acaba guanyant el no-res, entorn del qual es clou finalment l'urpa eixarreïda, abans àvida de possessió i domini.

\section{2. "CANT D'UNA PRESÉNCIA*}

En els anys de postguerra, Carner assumeix novament, com en algunes obres de la seva joventut, la condició de poeta al servei de Catalunya, consciència cívica de poble, abanderat de l'ideal, del somni comú. En aquesta segona modalitat, que anomenem civil, el poeta no parla en tant que simple espectador del món, ni tampoc com a individu dins o contra el món, sinó com a membre d'una collectivitat, de vegades assumint sobre ella una mena de guiatge patriarcal. La poesia, aleshores, esdevé un instrument de comunió, de conscienciació històrica i moral, de fixació i mitificació de la identitat nacional, d'expressió d'inquietuds i esperances sobre el destí de la comunitat.

La gran diferència entre els poemes civils noucentistes i els de postguerra es troba, també en aquesta modalitat, en la veu del poeta, condicionada pel pas del temps $i$ els avatars de la història. Així, el to optimista i exultant d'aquell Carner que modelava el somni noucentista ("Cançonetes del "Déu-nosdo"» $\mathrm{i}$ altres poemes de l'estil) ha estat substituït, en la majoria dels casos, pel to nostàlgic, adolorit i elegíac de l'home cansat $\mathrm{i}$ vençut que, malgrat tot, s'obstina a proclamar la seva fidelitat al «tros nadiu», i l'esperança en un futur més clar.

Són aquests poemes, d'entre tota la poesia carneriana de postguerra, la part més estudiada i antologada, per raons que probablement escapen a l'estricta valoració poètica. Configu- 
ren el que en podríem dir poemes d'exili, entenent com a tals aquells que tenen com a tema l'evocació de Catalunya's i la reflexió cívico-patriòtica sobre la situació del país, La major part foren publicats al recull Llunyania (1952), de títol prou significatiu, i després, a Poesia, inclosos en l'última secció, ABSĖNCIA.

Els inèdits de 1957 afegeixen una reduïda però significativa mostra a aquests poemes d'exili.

Uns pocs tenen un caire més subjectiu i líric, expansions de pura enyorança; els altres, profètics i exhortatius, solidaris, incideixen més en el moment històric.

Seria un bon exemple del primer cas el poema "De lluny estant", que obre la secció ABSĖNCIA. És un poema d'una simplicitat magistral. Comença amb una evocació del paisatge tardoral de Catalunya (a través de l'enumeració d'unes imatges representatives, com si es volgués captar l'essència del paisat$\mathrm{ge}^{16}$ ) de gran poder evocatiu a mesura que flueixen els versos: "cala", "pàmpol", "pi", "romanis... La terra llunyana sembla que es faci present al conjur d'aquestes paraules. Però, a l'últim quartet, irromp amb força el jo líric, i de l'enyor passem, dins la mateixa austeritat expressiva, a la desolació, en una brusca ruptura antitètica (de l'enllà a la immediatesa, del passat al present, del paisatge entranyable als «bedolls» i el «boiram»), Els dos últims versos tenen com a nucli la patètica imatge de l'àngel «amb el glavi tort»: l'alat missatger de l'ideal, de la veritat i de la llum, convertit en símbol de la desolació, de l'esfondrament de l'ideal, del retorn impossible. Heus aquí el poema:

is El mot Catalunya no hi apareix mai, sempre substituit per perífrasis alllusives com "tros nadiu", "mare", "clos pairal", etc.

${ }^{16}$ Aquesta mena de reducció ja la trobem al primer sonet del tríptic "L'altre enyor", publicat a Paliers, i una de les peces fonamentals de la poesia civil carneriana. 
Qui veiés, quan l'estiu s'acomiada, el cami-la serp blanca i somrienti, al marge d'una cala refiada, el pàmpol mort sota d'un pi vivent.

Qui veiés una dansa damunt l'era i una serra morada enllà de mi; qui topés un aloc de torrentera o enmig d'un pedruscall, un romaní.

Més val, però, que a aquests bedolls s'acari el meu esment, i a aquest boiram somort. En mos camins d'un temps, hom pot trobar-hi un àngel trist amb el seu glavi tort.

Uns procediments expressius i un resultat semblants torbaríem en el poema «Nadal I943 al tròpic»: l'evocació del Nadal de la infantesa (els elements típics són en aquest cas la molsa, l’arboç, els flabiols) ve contrapuntada pel present (l'exili, la segona guerra mundial): l'única cosa que pot fer és recordar (aquí els elements de la terra estranya són «cactus i atzavares", ja que el poema fou escrit a Mèxic).

Al costat de l'enyor, la fidelitat és un dels sentiments predominants en els poemes d'exili. D'entre els inèdits de 1957 , cal remarcar el titulat «Ulisses pensa en Itaca», de versos decasíl-labs sense rima. ${ }^{17}$ Aquí Carner acut al correlat mític de l'heroi de l'Odissea, paradigma del gran absent. Segurament per això el poema fou inclòs a la secció LLEGENDARI, malgrat que per evidents raons també hauria pogut figurar a ABSĖNCIA. Contra el que és habitual a LLEGENDARI, aquí la identificació entre la situació personal de Carner i la ficció mítica queda prou evidenciada, i és fent-ne aquesta lectura que el poema cobra una nova dimensió. El mite és una màscara. No

${ }^{17}$ Les seves terminacions poc freqüents semblen voler imitar els estramps medievals. 
sols Itaca és invocada des de l'absència com una «amenaçada pàtria difícil», sinó que parla del poble d'Itaca («un poble que rondina»), en termes que ens fan pensar en les famoses "madres del alma catalana", de Maragall (orgull, individualisme, irreverència, laboriositat, amor a la llibertat...):

\section{[...] De naixença}

cascun és príncep, baldament el cridin per un malnom i la gossada el bordi.

Qui de deixies viu, tot alzinant-se diu: "Ei!n, d'un cop de colze a qui governa. Increpadors, també, que no perdonen traveta o surt als Immortals mateixos. Només la feina els mana i els ajusta; són bé com són, tot $\mathrm{i}$ aprenent dels altres, $i$ encar que tot desig els atalenti llur poc suporten si ho gaudeixen lliures.

Així és com veu el seu poble aquest Carner caracteritzat d'Ulisses. No l'idealitza, sinó que el veu de manera realista, amb les seves limitacions i mancances. Tanmateix, Ulisses no dubta a confessar, quan el poema es centra en ell, la seva fidelitat al seu poble, el seu amor per Itaca:

Lluny de les teves cales i pendissos, amb fat que va als extrems de la fortuna, jo, tant en l'honra com solcant onades d'adversitat, les adients al savi, m'he depassat, per a no mai decebre't; temps a venir, si visc en la memòria dels més remots, soni el meu nom encara veí del teu, i els meus treballs et siguin ofrena, cant, devoció per segles. (vv. 26-34)

Al final, després de dues tirades de versos que s'ajusten més 
al mite ( $i$ on seria arriscat buscar més connexions amb Carner), hi ha una al-lusió a la mort, present en bona part de la poesia carneriana de maduresa. Res no el satisfaria tant, arribat l'últim instant,

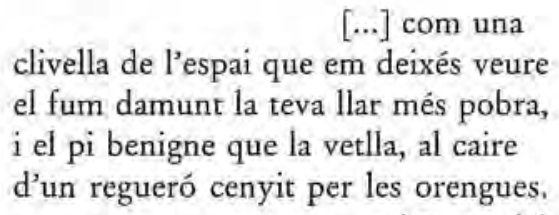$$
\text { (vv. } 57-6 \mathrm{r} \text { ) }
$$

La fidelitat apareix sovint lligada amb l'esperança en el futur. Així ho veiem en "Salm de la captivitat", un poema en què el correlat homèric és substituiit pel bíblic, també habitual, com hem vist més amunt, en la poesia de Carner. Si aquell poema fou inclòs a LLEGENDARI, aquest figura dins VERB. Però n'hi ha prou amb una lectura superficial per adonar-se que, més que un poema religiós, es tracta d'un poema d'exili. El jo deixa lloc a la primera persona del plural, com si el poeta parlés per tots. Ja al primer quartet apareix nítidamet la imatge del poble abatut i derrotat, i l'al-lusió a la dictadura franquista és tan clara que sorpèn que aquest poema passés la censura de l'època.

Cada mirada nostra és entelada;

cada mot nostre, esclau.

Cada dia atueix les nostres vides

qui ens mena amb jou per odi de la pau.

(vv. $[-4)$

A partir del segon quartet el poema esdevé una invocació a Déu: «Oh Déu que ens assabentes amb el càstig!». A remarcar la velada autocrítica que conté aquest vers, manifestada també en altres poemes. Déu castiga el poble, com el Jahvè de l'Antic Testament, perquè el poble ha pecat, perquè s'ha 
desviat del camí recte. La dura prova del present, la humiliació, és vista com l'expiació d'aquesta falta.

El tercer quartet, després de clamar perquè reneixi l'esperança, acaba amb una nova referència a la dictadura:

Refếs els nostres dies amb saba d'esperança;

cruel és tot poder si ton esguard en fuig;

que et resti obedient qui se't confia:

seră desfet qui es deia armat pel teu enuig.

(vv. 9-12)

El sisè i penúltim quartet expressa l'esperança en un futur, com si el somni de la Catalunya ideal que, anys endarrera, Carner havia contribuït a definir, encara fos possible de realitzar.

Soni la nostra veu, que ara ens ofeguen, en càntic immortal.

Salva, a l'abric de renaixents columnes, el nostre clos pairal.

(vv, 21-24)

$\mathrm{El}$ poema-salm es clou amb una gairebé previsible al-lusió a la mort; fíns i tot aquí, però, hi regna l'esperança:

I que l'or de la teva solellada

consoli les afraus, coroni el cim

quan ton alè ens retiris

$i$ encara ens facis terra d'aquella d'on venim.

(vv. 25-28)

Un altre poema de fidelitat i esperança és «Cant d'una presència». Catalunya hi és invocada com una "mare endolada». Alguns versos fan pensar en els himnes patriòtics de tradició vuitcentista, com és ara aquest quartet, amb la seva metaforització de la senyera: 
Amb ta saba en mi, jo só teu encara;

teu que em vas voler, mai no m'has perdut;

mou encara el vent en tes quatre flames

foc invulnerat de ma joventut.

(vv. 9-12)

També es podria incloure en aquest grup el poema "Vetlla de festa", un cant d'esperança amb què Carner va voler cloure la secció LLOC, dedicada a descriure i fixar poèticament el paisatge de Catalunya. És com a poema civil, com a allegoria de la represa, com a proclama de fe en el futur-i el segon quartet és ben inequívoc en aquest sentit-, i no com un poema purament arbitrari i descritiu, quan ateny el seu valor:

Es sent, amunt del cel, la batallada $i$ en dolç esplai el nostre cor sospira, i cada cosa amb nou posat ens mira, tota en delit de la vinent diada.

Ja, malgrat el seu urc d'invulnerada, la iniquitat tremola en sa cadira; perquè fórem recòndita guspira demà farem un salt de flamarada.

Es cobriran de flor tanques $i$ espones, s'esvairan el plany i l'agonia, un destí jove saltarà a la sella.-

L'ull del desig ens mira entre les ones, i el cop de vent, en sa frisança pia, blancs imperis de l'aire desgavella.

Ja hem dit abans que la modalitat civil era, juntament amb el poema $\mathrm{Nabi}$, la parcella més estudiada de la poesia carneriana de maduresa. Les tendències crítiques predominants als anys 60 hi deuen tenir molt a veure. Des d'òptiques realistes 
i polititzants, es tendia a sobrevalorar aspectes extrínsecs al fet poètic en si. La denúncia, la sàtira, la descripció realista, la consigna ideològica i la reflexió cívica van arribar a eclipsar valors poètics més profunds. La poesia fou instrumentalitzada, o sacrificada, en benefici d'estratègies polítiques. Només així es comprèn el ressò que van arribar a obtenir obres com La pell de bran o alguns reculls de Pere Quart, per posar només dos exemples. En aquell context, es de justícia remarcar que la poesía civil de Carner ha resistit millor el pas del temps que la majoria d'obres del moment.

\section{3. "LES FORCES DEL PREGON"}

La tercera modalitat és la que anomenem simbòlica. Quan Riba va dir de la poesia carneriana que era "un fons sense espais metafísics darrera». ${ }^{18} \mathrm{Cal}$ entendre que es referia a la poesia noucentista $-\mathrm{O}$, si volem, a la modalitat arbitrària-, la qual, d'altra banda, és l'única que ell va analitzar detingudament. Seria un error, però, aplicar les seves teoritzacions al conjunt de la poesia carneriana. La veritat és que, per les raons que sigui, Riba no va dedicar cap escrit remarcable a la producció carneriana posterior a 1920-justament quan Carner començava a incorporar noves modalitats, i quan els aespais metafísics» feien acte de presència en la seva poesia. Aquesta limitació, val a dir-ho, ha condicionat una bona part de la crítica posterior.

La modalitat simbòlica comprèn un conjunt de poemes -minoritari si es vol, però d'un valor extraordinari-que, com indica el nom, es podrien situar dins la tradició de la poesia simbolista, la deu més important de la lírica moderna. A diferència de la modalitat arbitrària, el poema depassa aquí l'àmbit de la realitat sensible, lògica, racionalitzable, i s'aven-

${ }^{18}$ Carles Riba, Obres Completes, 3 (Crítica, 2), cit., pàg. 5 I. 
tura pels camins de la immersió existencial i la indagació metafísica, de vegades reduida a un calfred, un vertigen; es projecta, sovint només en forma d'interrogant, cap a la part ignota de la realitat, el domini de les forces obscures, del misteri, del somni-o del malson. La paraula poètica pren aleshores una nova ressonància. Constreta $\mathrm{a}$ anomenar l'innominable-millor dit, a suggerir-lo-, és sotmesa a un procés de dilatació significativa, de dispersió polisèmica, i es converteix en un escandall amb què el poeta tempteja l'inconegut, $s^{\prime} a-$ proxima a l'enigma. Mentre que en la modalitat arbitrària els mots cerquen la precisió i la plasticitat per tal de produir o reproduir una realitat que el lector percep com a tangible i equivalent a la que l'envolta, en la modalitat simbòlica el llenguatge s'envolta d'una aureola d'inconcreció i vaguetat, ja que, per poder aprofundir més, la paraula s'ha de buidar abans del seu sentit referencial. Augmenta el grau d'abstracció, i la metàfora, unívoca, esdevé símbol, de significació múltiple, contextual i intuïtiva. Estem parlant d'un procés fonamental per comprendre la poesia postsimbolista del segle XX. Amb la modalitat simbòlica, Carner, sense abandonar mai el seu peculiar classicisme arbitrari i figuratiu, s'incorpora de ple en la gran poesia del seu temps.

Pràcticament absent de la poesia carneriana de l'etapa noucentista, la modalitat simbòlica apareix en poemes dels anys 20 - entre ells l'emblemàtic "Nocturn", que obre la secció LES NITS de El cor quiet - i es consolida, alternant amb les altres modalitats, en la polifacètica producció de postguerra, de la qual, com hem dit, els inèdits de I957 constitueixen el compendi més representatiu i variat.

Vegem, com a exemple inicial, el sonet $\alpha \mathrm{A}$ trenc de dia». Comença amb una enumeració d'inquietants figures de malson dins una escenografia espectral, ben característica d'alguns d'aquests poemes. El primer tercet ens presenta el «dorment" perdut en una «indecisa cova», que no és només la del malson, sinó també la de la mort, la incertesa, la disgregació 
de la personalitat, el no-res. Finalment, però, la confabulació d'ombres que sotgen l'esperit del poeta és desfeta pel triomf de l'àngel del matí-que simbolitza la Ilum, la vida, la veritat, Déu:

Llum fantasmal, arborescents falgueres,

lloc on rodà l'aquàtica avior,

signes perduts en boires volanderes,

fites errants del seny i de la por,

negres ocells d'immemorials corberes, arbres gements i sense cap saó, tels, teranyines, ombres fugisseres que encerclar-me voldríeu on no só:

tot fou ordit en la indecisa cova en mi nascuda, vista enllà de mi, on el dorment avança $i$ no es retroba.
Ja, peró, glavi nu, per alt camí, l'inesperat arcàngel del matî
el cel abranda amb la certesa nova.

Semblant a aquest sonet (i en certa manera complementari) és el poema "Visita», que té també com a protagonista "el dorment» i l'acuit de les ombres del malson, que davallen cap a ell «per graons estel-lars i buits pendissos». El sotgen com per apoderar-se'n i són finalment dispersades. S'explicita al vers final que són les ombres de la mort.

Aquests serien exemples del Carner que s'abeura en les aigües del simbolisme. La qüestió del perquè no ho va fer abans dels anys 20 ens portaria potser massa lluny. Té a veure, és clar, amb el Noucentisme i amb la tasca de fixació i normativització de la llengua. En aquell context, en una llengua que encara havia de superar la fase normativa i definidora, seguir els corrents de la lírica moderna i potenciar els contorns di- 
fusos i vagues del mot tenia els seus perills_la fallida llengua de Maragall, mirant d'arribar a la simbolització pel camí de la paraula viva, ho exemplifica prou bé. Era obvi que la llengua catalana no estava preparada per a aquest tour de force. Es entre altres coses per això que els noucentistes van veure la necessitat d'imposar un nou classicisme, tornar als límits $\mathrm{i}$ la contenció-emotiva, ben cert, però abans que res verbal. Eugeni d'Ors ho veia molt clar. L'any 19ı2, en la glosa «Libació a Hermes», escriu: "Cada mot pot tenir una ressonància infinita: però l'excellent escriptor és el qui sap renunciarhi sovint. Els grecs no se'n valgueren mai». Calia, per a ell, renunciar al símbol. En canvi, era molt més apropada a la seva concepció clàssica de l'art l'opció objectivadora i arbitrària de Carner.

A partir de l'any 20 es donen tres condicions perquè Carner, sense abandonar la fíguració objectiva, incorpori una nova modalitat a la seva obra: en primer lloc, es desvincula materialment de l'ampli moviment cultural i polític que anomenem Noucentisme -i que com a tal moviment ja estava llavors a les acaballes; en segon lloc, la llengua catalana, passada la quarantena a què els mateixos noucentistes la van sotmetre, ja s'assemblava molt, en tots els aspectes, a una llengua normal. Finalment, el ventall de coneixements i lectures de Carner s'havia ampliat considerablement, i s'havia posat del tot al dia. Si a tot això hi afegim la maduració personal i el natural desig de renovació, podem comprendre que la poesia carneriana busqués nous camins temàtics i formals, mirés d'aprofundir en el misteri de l'existència i s'omplís d'inquietuds metafísiques.

De vegades, el poema parteix d'una simple convulsió interior, un estremiment, l'estupor d'existir. Aquest és el cas del poema «Sobtadament»:

Sobtadament, una dolçor em diu: - ¿D’on vinc? ¿Qui só?- 
La terra, com meravellada, es fa més tendra a la petjada.

Hi ha un raig de sol damunt la margenada sobre una flor d'humil color.

I quan ja fina la dolçor encara em diu: $-i D$ ’on vinc? ¿Qui só?

Un altre poema, "La peixera i el dubte», adopta la forma de figuració al-legòrico-metafísica amb un toc d'ironia; els homes hi són vistos com peixos atònits en la gran peixera de Déu, joguines de "les forces del pregon", fiblats per mil interrogants-molt abundants en els poemes d'aquesta modalitat:

- ¿Quin vent hi haurà demà? ¿Què hi fem al món?

¿És que l'onada ens mena $i$ afaiçona?

¿Té cap virtut el pensament d'un peix?

¿Só jo, mirant, qui fa la mar rodona?

¿O só mar o peixera jo mateix?-

(vv, 10-14)

També té un punt d'ironia i de típic enjogassament carnerià el poema "Diàleg", en què el poeta, sotmès a les limitacions humanes, conversa amb la seva ombra, pura $\mathrm{i}$ incorruptible, "filla d'un besar del dia i de la nit». I en el poema «Himne dels seguidors d'Osiris» (que clou la secció LLEGENDARI), Carner conjuga la modalitat simbòlica amb la ficció mítica, que hi fa de simple embolcall. Són dues mostres més de la versatilitat creativa de Carner.

Un dels símbols reincidents de la poesia simbolista, l'àngel, que ja hem trobat en «A trenc de dia», apareix en el poema "L'oblit d'un àngel". Com a símbol, hi pren les mateixes connotacions positives: la força creadora, la llum, la vida, el missatger de Déu. Però aquí la seva intervenció provoca indirectament, al final, la irrupció de les forces obscures, la 
mort, la desolació. Un àngel, ens diu el poema, deixa caure en un indret «el propòsit d'un llac» (no és un llac real, sinó un "propòsit», una intenció, un projecte que encara ha de germinar). En els dos quartets següents es descriu com seria (els verbs són tots en subjuntiu o condicional per remarcar la irrealitat de l'escenari, pura promesa) aquell lloc. L'escenari paradisíac-simbòlic_contrasta fortament amb el que és descrit en els dos últims quartets, després que l'àngel, havent oblidat l'indret, no hi hagi tornat més. Aleshores, la desolació i la mort, els contraris de l'àngel, se n'apoderen:

Del seu enyor s'esgrogueí la terra i, amb cor ombriu, va sospirar l'avet.

Un pastor va penjar-se d'una soca, cap trista flor no comportà els eixuts, més revellida es va sentir la roca i tres ocells partiren, decebuts,

(vv. I $5-20$ )

El sonet «País perdut» ens presenta el procés invers: el món que neix, del no-res a la incertesa de la vida. No és un simple cant a la primavera-com tants del Carner noucentista-, sinó que s'hi endevina una clara dimensió simbòlica. Només cal fixar-se en l'ús dels ocells com a símbol, tant en el poema anterior com en aquest. El primer quartet, d'una gran sobrietat expressiva, consta de quatre frases, una per vers:

Ja de la pedra eixuta lluien els cantells.

El vent aconduïa fistons en l'herba tendra.

Un ametller floria sota d'un núvol cendra.

Pel gris lleuger de l'aire venien nous ocells.

(vv. I-4)

Al segon quartet s'estableix una identificació entre la realitat exterior i la interior, sumides encara en la quietud, davant la 
invitació a la vida: «La primavera feia com jo». En els tercets, en canvi, s'hi expressa una punta de reticència. La primavera, personificada com a figura maternal, no gosa lliurar-se del tot a la promesa de la vida i deixar que els sentiments brollin espontàniament; els reté com una mare poruga. També aquí hi apareix, doncs, el contrapunt de l'ombra, sempre present en els poemes de maduresa de Josep Carner:

I al davantal cobria la seva nierada, sense dar pas, poruga que alcessin la volada el somni, l'esperança, el dol en el desert.

Homes i déus, joguines del plany i de la dansa, en començant a viure sospiren de recança: deixies del no ésser que afrontaran l'incert.

(vv. 9-14)

Aquest «no ésser», identificable amb el no-res, és un altre dels temes recurrents dels poemes que estem estudiant. Sovint s'associa amb la boira, com hem vist a «Sota una boira de tardor", poema que, tot i que l'hem situat dins la modalitat arbitrària, conté una considerable càrrega simbòlica. Josep Carner assajà diverses variacions sobre aquest tema. Les més destacables, al costat del poema esmentat, són «Boira" (no publicat en llibre fins el 1957) i «Ostende, 31 desembre 1949" (publicat a Paliers). Curiosament, són el primer i últim, respectivament, de la secció LLUNARI, com si Carner hagués volgut situar la boira com a començ i fi de la roda de les estacions. "Boira», en tirades de versos polimètrics, descriu també l'esborrament de la realitat tangible, situació propícia al fantasieig i la divagació metafísica:

A tot arreu són anul-lades les parences: oh quina avinentesa perquè es repensi el món! Les veus, a penes han deixat la boca, no saben de qui són. 


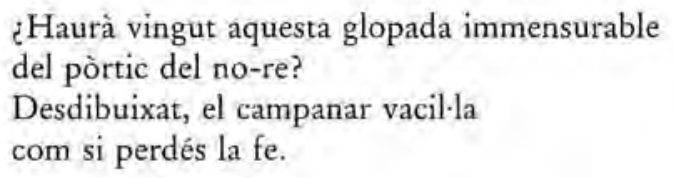

Els homes són l'ombra d'una ombra, cada finestra, secret segellat:

tot el viscut es nega en un flotant record de l'increat.

El poeta especula sobre la possibilitat d'una transformació del món, «dibuix inconvincent», cap a una realitat millor. Però, finalment, la boira escampa, i tot resta igual com era.

La desil-lusió davant la realitat s'objectiva d'una manera magistral en el plor de l'estàtua que ha acompanyat el poeta en les seves cavillacions:

I veig encara en una plaça vella

- molsa i rovell, com en un mal d'enyor-

que un floc darrer posa una llàgrima en la cella

d'aquell heroi de bronze

ara indigent $i$ mut.

I ell, per dolcesa de la boira, esplaia

el seu remordiment d'haver viscut.

(vv, 40-46)

La poesia de tradició simbolista, entesa com un instrument de projecció metafísica, converteix sovint la mateixa experiència poètica en un acte transcendent en el qual es condensa tot el misteri del món, en tant que Creació, especialment quan no es limita a reproduir una realitat donada, sinó que indaga enllà de les aparences. L'escriptura és un intent de lluitar contra el no-res. Per això, com deia Maragall, tot el misteri de la vida i la creació es troba en la paraula poètica, que d'altra banda té la capacitat de fixar un món absolut $\mathrm{i}$ intemporal, quintaessència de la realitat. 
"Creació del poema" (publicat a Paliers) és la peça cabdal d'aquest subgrup de poesia sobre la poesia. Entre els inèdits de 1957 també trobem variacions entorn del mateix tema. Un exemple seria «Clara nit».

El primer dels tres quartets de què consta el poema descriu un marc de desolació, un escenari emboirat i nocturn, lleugerament fantasmagòric, feu de la mort i la devastació, especialment per l'esment al «jardí desert»:

De la boira l'errívol simulacre en els pendissos de la nit es perd. El cel estrien viaranys de nacre, la lluna mira aquest jardí desert.

(vv, I-4)

És al segon quartet on s'explicita la funció que correspon a la poesia:

Cada flor, cada veu fou un emblema irreal, que es migrava a mig camí.

Oh somni, menys durable que el poema!

El vers, cantant, repoblarà el jardí.

(vv. 5-8)

Remarquem que el terme «emblema" (signe visible d'una idea, representació d'una cosa abstracta) equival a símbol. El jardí, ara desolat, era ple de vida. Però les flors i les veus eren «irreals», en tant que efímers, sotmesos a la destrucció. La realitat és un somni, "menys durable que el poema». L'absolut es refugia en el poema, que eternitza els emblemes, els sostreu de la seva fugacitat i els fixa: «El vers, cantant, repoblarà el jardí». La poesia, doncs, té una funció restitutòria, creadora. La mateixa idea és la que trobem al poema "Un dring» on després d'una aproximació al símbol, a la paraula poètica, amb reminiscències maragallianes («Una paraula / agrisada en el 
costum, / que, de cop, es torna llum») es remarca la seva intemporalitat:

\author{
Ves per quin atzar fou ella \\ qui lluís i qui fenyés \\ del tothora la durada \\ i la força del mai més.
}

(vV, 10-13)

Tornant a "Clara nit", la realitat absoluta, essencial, s'associa finalment amb la visió interior. El poeta tanca els ulls i pot veure el jardí en la seva esplendor. Aquesta invocació és l'equivalent de l'acte poètic:

Cloent els ulls, entre les mans la cara, veig en el pobre clos desemparat ombres antigues, somrient encara, i flors que hi foren i el gran pi llampat. (vv. 9-12)

$\mathrm{Al}$ poema «El noble do» (que clou la secció COR QUIET), l'acte poètic es troba simbolitzat en el llançament d'un palet a l'aigua d'un estany: l'encreuament de la perdurabilitat (la pedra tornejada pels segles) i la fugacitat (el ròdol efímer d'aigua); la fusió de l'art i la vida.

Dir molt en un mig dir, seria mon afany.

I perquè passi un signe de mi damunt l'estany,

em bastarà un palet molt lleu, color de rosa (on, tota amagadissa, l'eternitat es posa),

perquè em dibuixi un ròdol—a penes nat, perduten l'aigua del silenci i de la solitud.

En aquest context de reflexió poètica agafa tot el sentit el 
poema "Himne a l'hivern». Comença, com és de rigor, amb una descripció del paisatge hivernal. Ens trobem immersos, novament, en l'escenografia de la desolació.

Mossegues el meu dit

i cadascú rondína de tos greuges;

el sol has decandit

i la seva alta caminada abreuges;

el fontinyol és mut;

del niu s'esfilagarsa la deixia;

senyals del que ha viscut

jeuen en holocaust $i$ en agonia;

no sona cap afany

dalt del marge morat de les veredes;

és ja gargot i plany

el palau gronxadís de les arbredes.-

(vv. $1-12$ )

Semblaria, per aquestes tres estrofes inicials, que ens trobem davant un poema purament descriptiu, una elegia arbitrària, amb la típica personificació carneriana de l'hivern, apostrofat directament des del primer vers.

Les tres estrofes següents, però, ens mostren una nova dimensió, més profunda i abstracta, del poema:

Gran lineal ardit, fon en blanca unitat camp i bardisses;

llibera l'esperit . dispersant les imatges estantisses!

Hostil a l'abrigall

de tota guarnidura pampolosa, aviva amb ton estrall l'Ariadna no prou imperiosa. 


\author{
Si menys durà que el vent \\ tanta inútil ufana sense ofrena, \\ tu mostres, resplendent, \\ l'essencial del cim i la carena.
}

(vv. 13-24)

No ens trobem, doncs, davant el típic plany sobre els estralls del fred i la devastació hivernal. Aquí, invocat més que blasmat, l'hivern és vist com un element positiu, com una força purificadora, i es converteix en símbol de la puresa espiritual. En despullar la natura d' «imatges estantisses» i d'abrigalls superflus, l'hivern revela la unitat essencial del món, el perfil $\mathrm{nu}$, la línia pura, allò que resta quan es dissol la guarnidura estival, «tanta inútil ufana sense ofrena».

L'aplicació d'aquesta figuració al-legòrica, l'hivern essencialitzador, a l'activitat poètica s'explicita al setè i últim quartet:

Habita el meu país.

Gela'm, si cal, als llavis la paraula;

i amb el teu dit blavís

del fàcil fruit despararàs la taula.

(vv. $25-28$ )

Carner expressa, en aquests versos, el desig que la depuració hivernal que primer ha descrit, i sobre la qual ha reflexionat després, es produeixi també en la seva poesia. L'hivern i les seves metamorfosis són només un pretext per acarar-nos a una fínal meditació sobre la poesia com a acte espiritual. Són quatre versos d'una gran rellevància, justament perquè són representatius d'unes característiques que trobem en una bona part de la poesia carneriana de maduresa, i que ja hem destacat en les pàgines precedents: sobrietat, despullament, austeritat, simplicitat. Carner advoca per una poesia més nua i essencialitzada, de la qual aquest mateix poema n'és un bon exemple. Complementàriament, hi trobem també, més o 
menys explícita, una certa crítica contra una poesia menys exigent, més superficial, el "fàcil fruit», la *inútil ufana»-com si Carner assagés una autocrítica sobre una part de la seva poesia del passat. En definitiva, "Himne a l'hivern» conté, en embrió, una ars poètica de maduresa.

I el mateix podríem dir, salvant les distàncies, del breu poema "A mitja veu», una peça gaírebé circumstancial que, no obstant, coincideix en el contingut global:

Cal, oh senyora de la flor i el floc, més que no pas enginy ì melodia, el mot que un món implícit ens desnia; més que cap llavi, l'esperit del foc.

La frontera entre la poesia simbolista i la poesia religiosa ês de vegades ben difícil de dintingir. En tots dos casos, la poesia vol ser un instrument de percepció d'una altra realitat. És per això que, com a afegitó a la modalitat simbòlica, col-loquem aquí els poemes religiosos carnerians. No ens referim pas als poemes narratius bastits a partir de mites biblics, que hem situat en la modalitat arbitrària, sinó aquells que es centren en el misteri de Déu i en l'expressió de la fe. Alguns altres d'aquests poemes religiosos, més personals i íntims, se situarien ja en la frontera de la modalitat introspectiva.

Entre els indèdits de 1957 , les dues aportacions fonamentals a la poesia religiosa carneriana són *Cant del just» $\mathrm{i}$ «Prec de la darreria».

Aquest últim, paràfrasi d'un verset bíblic com consta al subtítol, tanca la secció VERB i és, sens dubte, un dels millors poemes religiosos de Carner. La traducció del verset en qüestió obre el primer quartet $i$ anuncia el tema central:

Tu que el sol vas encendre al firmament, en el cor de la fosca fas estada. 
Déu, creador del món, no es fa present als homes, ni als bons per a la recompensa, ni als pecadors per al càstig. Aquest és un tema tractat també a Nabí. Davant del silenci de Déu, l'única solució és la fe, amarar-se de la seva presència invisible:

Si ton rocall és aquest vell empriu, en cap deler ¿què val de gemegar-hi? Sols el vivent que el teu silenci amari munta com l'arbre margener del riu.

(vv. 13-16)

El poema es clou en una invocació a Déu:

Nom sobre nom, albir omnipotent que saps alliberar-nos de servatge, en el darrer tombant del meu viatge pren-me en la teva revolada ardent.

(vv. 37-40)

\section{4. «DOL, SOLITUD, ENYORAMENT L OBLIT»}

S'ha dit que la poesia carneriana presentava un tal punt de distanciament impersonal i d'ocultació del jo que a partir de la seva lectura mai no podríem tenir accés al món íntim del poeta. Però aquesta asserció no és del tot certa, i sembla més aviat fruit de la ja esmentada tendència a reduir tota la lírica carneriana al simple clixé noucentista i a aplicar-hi globalment uns trets que només són privatius d'una part, bé que molt important.

Carles Riba escrivia de Carner, l'any 1920, a propòsit de L'oreig entre les canyes: "Demanar-li que es renovi, simplement, és una incomprensió (...); però demanar que es renovi, ell, el de la perfecta salut, per un turment que li trasbalsi te- 
mes i esperit, no passa d'ésser una romàntica impertinència". ${ }^{19}$ Però la veritat és que, influït o no per «romàntiques impertinències", Carner va renovar la seva poesia, i no sols en el sentit d'incorporar alens simbolistes i ressonàncies metafísiques a la seva obra, sinó també en la direcció d'introduir el jo dins el poema d'una manera més decidida i franca.

La irrupció d'aquesta modalitat, que aquí anomenem introspectiva, es produeix també al llarg dels decisius anys 20, si bé els poemes que s'hi poden adscriure sovintegen més a partir de la dècada dels 40 . El jo deixa d'exercir una funció purament decorativa - el jo espectador-per esdevenir el centre i la matèria del poema; no és tampoc el jo més o menys funcional que vagava en molts poemes simbòlics, solitari en la nit o en la boira, aprofitant el desdibuixament de les aparences, l'esborrament del món, per percebre la pulsió metafísica i la revelació de l'inconegut. El jo de la modalitat introspectiva té una dimensió més íntima, és el jo d'un individu sotmès a unes determinades contingències biogràfiques, anímiques i sentimentals. La poesia, així, esdevé un instrument d'autoconeixement $\mathrm{i}$ de fixació d'aquest món íntim personal, amb explicitació de sentiments, estats d'ànim, records...

Dins els inèdits de 1957 trobem una bona mostra, $\mathrm{i}$ ben diversificada, d'aquesta modalitat.

Els estats anímics que s'hi manifesten es podrien reduir a dos: l'assenyament i la desolació.

El tema del seny no mostra gaires canvis en relació a les seves primeres formulacions en la poesia carneriana dels anys 20. El cor quiet (1925) és un títol que fa referència a aquest estat anímic; convertit en COR QUIET, dóna nom a una secció de Poesia que aplega, a més de poemes provinents del llibre esmentat, altres de L'oreig entre les canyes, El veire encantat, La primavera al poblet $\mathrm{i}$ alguns inèdits. Val a dir, d'altra ban-

19 Obres Completes, 2 (Critica, I), Ibid., pàg, 209. 
da, que una bona part dels poemes d'assenyament es troben escampats en les altres seccions.

En certa manera, l'assenyament és un estadi lligat al cicle vital, a l'evolució personal, i sembla que en Carner aquest estadi es posa de manifest quan esdevé una persona madura, amb una família i una feina estable, resignat a la seva sort, fins a cert punt feliç -és la imatge que en dóna Pla al seu Homenot-, però també més reflexiu, més sensible al pas del temps i a l'envelliment personal. Es tracta en definitiva d'una experiència ben normal; però la novetat, en la poesia carneriana, és trobar-la explicitada en termes subjectius, sense el recurs de l'objectivació, amb el qual tantes vegades havia manifestat, indirectament, la joia i la benaurança, sentiments predominants en la seva etapa noucentista.

En el procés de destillació i manteniment posterior d'aquest estat d'ànim tampoc no es pot descartar l'influx, tan important en Carner, de la lírica xinesa, on la serenitat, la resignació, la quieta felicitat, l'aspiració al seny i a la saviesa són els estats anímics predominants. Algú ha parlat també d'una filosofia epicúria..$^{30} \mathrm{~L}$ 'assenyament carnerià expressa igualment un cert fatalalisme $\mathrm{i}$, a voltes, un dolor contingut, la «dolça pena» que amoroseix el cor («Bé cal un toc d'angoixa, de curta melangia», ens diu a "Primavera recobrada"), sense arribar encara a accents patètics i esqueixats. Tot plegat configura una lírica de clars continguts subjectius, però encara dins un cànon classicitzant, lluny d'estridències romàntiques.

De vegades el jo només apareix al final per donar sentit al poema, com en el cas d' "Ajagut vora la font», o és encara una presència difusa, com a "Un camí», cançoneta d'estil noucentista si no fos pel seu grau d'abstracció i pel final pressentiment de la mort:

20 Antoni Marí, «Sobre el ideal del sabion, supl. Cultura de La Vanguardia, 9-11-1984. 
Oh lloc segur sense vivents! Cada any jo i tu som més parents;

que es va atansant la meva fi, a llum minvant, pel dolç camí.

(vv. 2I-28)

En els poemes d'assenyament la mort hi és al-ludida en un to de serena acceptació. Al sonet "Tardor sensible», després d'una recreació descriptiva de l'escenari tardoral als dos quartets, la identificació entre la natura i el jo, davant la proximitat de l'hivern / mort, s'explicita als dos tercets en un to de plaent conformació:

Serenitat com de llaurada feixa, paga i corona de l'humil fatic.

Vaig, cingle avall, a una darrera lleixa:

¿per què l'aire, talment, em sembla amic?

La vida em diu que tan suau em deixa perquè ho fa al so de la cançó que dic.

(vv. 9-14)

La mateixa simbiosi natura-ànima, emmarcadada també en un escenari tardoral, trobem a "Cant de tardor». Després d'una estrofa descriptiva, l'òptica subjectiva domina la segona:

El vell amic deixà el meu ròdol,

de mi l'amor es departí,

el meu secret resta a mig dir,

no cap afany es sent brogir;

lliures ja són, demés de mi,

l'arbre, el camí, la font, el còdol. 
La quarta estrofa conté també uns versos ben clarificadors:

\author{
entre l'estepa i el timó \\ hec una nova serenor: \\ el meu desert es fa claror; \\ el cel, pertót regalador, \\ entra al meu seny i l'acompanya.
}

(vv. $24-28$ )

La part final del poema no fa sinó insistir en aquest estat d'ànim, que mai no perd de vista l'horitzó de la mort:

Sota el coval, ran de l'abís,

freneu, marors, calleu, ventades;

tu, breu demà, baixa el pendís

no pas irat ni cellagrís

ni calcigant el pur país:

plau-te a allargar-me aquest encís,

premi final de les anyades.

Puix si ningú no em vol cercar,

tot se m'ajusta i em convida.

Mos ulls es paguen d'aire clar:

encara enjoia el cel tardà

la meva vida que se'n va,

i encara embostes deixa anar

la meva mà desposseïda.

(vv. $43-56$ )

El segon estat anímic que aflora en la lírica introspectiva de Carner és, com hem dit abans, el de la desolació. En aquests poemes, Carner ens obre el seu món íntim com no ho havia fet mai. Hi trobem, quasi sempre envoltat de paisatges tardorals o hivernals-que es repeteixen, ja ho veiem, obsessivament-, un home voltat dels fantasmes de la solitud, la vellesa, la mort, el no-res. En uns casos sembla imposar-se el 
pessimisme, gairebé el nihilisme; en d'altres, acaba resplendint l'esperança, normalment associada al més enllà, És una poesia nova en el repertori carnerià, i és sobretot aquesta, malgrat la seva qualitat, la que ha estat més ignorada per la crítica.

La poesia de la desolació ja es prefigura en uns pocs poemes de la dècada dels 30 . Es ben lògic pensar que són fruit més o menys directe d'algunes doloroses experiències personals. Aquesta relació és òbvia en poemes com «Plany a la mort de Guerau de Liost", inclòs-o més aviat encabit, car el seu to no encaixa gens en el més aviat vital i festiu del conjunta La primavera al poblet. També podem datar als anys $30 \mathrm{el}$ sonet «La desesperança», que formà part d'un recull guanyador de la Flor Natural als Jocs Florals de Barcelona de l'any 1933, però que no fou publicat en llibre fins Poesia, on apareix estratègicament collocat com a últim poema de la secció OFRENA: $=$

Es pon, livid, el sol; el fred pelluca ma pell; es plany la casa de sotracs. M'abasarda en el dia que s'acluca la pols que xiula traginant parracs.

És ja la mà de la dissort qui truca: finí l'estona dels destins manyacs. Un fosc ocell el meu pitxer trabuca; el vent tira per terra mos escacs.

Contra mon dol no trobaré sopluig; la mort, potser, més gentilment saluda. Garfit, debades tot em crida: «Fuig!»:

21 Per bé que en l'edició de I957 aparegué com a penúltim poema de la secció, Jaume Coll, en la seva recent edició de Poesia, el situa a l'últim lloc, desplaçant "L'estiu fecund al jardinet", que hi va ser posat accidentalment pels responsables editorials del llibre de 1957 . Coll, al prôleg, explica i prova a bastament el per què d'aquesta restitució. 


\section{el cor transit i l'amistat perduda, l'amor tornada impiadós rebuig i l'alta branca del meu pi rompuda.}

En poemes com aquest, Carner, l'anti-romàntic per excel-lència, s'aparta tant del seu particular classicisme com de la seva aproximació al simbolisme per adoptar- "madurat pel dolor", com va escriure Marià Manent-les formes i el to de la tradició romàntica. Aquí, la poesia deixa de ser una representació del món, de la realitat externa, i es subjectivitza. El món - la desolació exterior-hi és al-ludit per exemplificar i complementar la introspecció. El poeta ens parla d'ell mateix, fins quan parla del paisatge. I les reiterades al-lusions a l'hivern, les boires, el capvespre... en són bona mostra.

El mateix podem dir de poemes com "Hora foscant", "Alta nit», «Departiment», "Lleialtat» (poema que clou Poesia) o «Plany al cor de l'hivern». Aquest últim, magnific, ve contrapuntat per un esclat final d'esperança:

Ja només se m'adiu el cel tancat, el dia curt i l'esbarzer gebrat.

Só lluny de tot el que fou part de mi; ¿com tornar enrera en sepultat camí?

Alafeixucs, envolten el cor meu els quatre corbs damunt la neu,

els quatre corbs més negres que la nit: dol, solitud, enyorament, oblit.

De sobte, i al compàs d'un tremolor, es bada en el boirat un ull rodó:

l'obliqüitat d'un raig escadusser cossa de diamants tot l'esbarzer. 
Vull esperar de nou l'inesperat, oh pobra punxa que t'has fet esclat!

Ja el teu senyal enjoiarà mon cor, oh ram hostil que portes un tresor!

\section{Consideracions finals}

A manera de síntesi final, destacariem els següents punts:

a.- Les pàgines precedents són un intent d'analitzar un conjunt de poemes partint del que hem anomenat modalitat. L'anàlisi pot ser vàlida també per a la globalitat de la poesia de Carner, ja que entre els poemes inèdits o no publicats en llibre fins a Poesia hi ha mostres, i aquest és un dels principals valors del conjunt, de totes les múltiples facetes i tonalitats de Carner.

b.- La modalitat no és només una qüestió de tema, sinó més profunda. Cada modalitat imposa una escriptura diferent, $i$ afecta per tant altres vessants de l'obra poètica, com són el mateix llenguatge, el grau d'abstracció, les dimensions referencial o simbòlica de les al-lusions externes, l'assumpció d'una determinada tradició poètica i també la veu del poeta, el paper del jo dins el poema, des de la seva ocultació en la modalitat arbitrària fins a l'exhibició del jo íntim i personal en la modalitat introspectiva, passant pel jo-de vegades primera persona del plural-solidari i col-lectiu de la modalitat civil i el jo metafísic-o religiós - de la modalitat simbòlica. Quatre identitats o veus diferents per a quatre menes de poesia.

c.-Les modalitats no sempre es troben en estat pur, sinó que de vegades es mesclen i s'entrecreuen. Tot amb tot, no és difícil establir en cada poema una modalitat predominant. El poema "Ulisses pensa en Itaca", per posar un exemple, arranca d'un pretext mític; tanmateix, no costa gaire de veure 
que la modalitat predominant és la civil més que no l'arbitrària. El poema és, primer de tot, una evocació i reflexió del país llunyà, sota l'empara (o la màscara) del mite d'Ulisses, en qui Carner, des de l'exili, projecta i objectiva el seu enyor i la seva fidelitat envers la terra natal.

d.- Dins cada modalitat s'observa una considerable varietat de tons: del més vital i àgil, reminiscència del Carner noucentista, fins al més greu que s'imposa en la maduresa, amb contínues referències a la mort, $i$ amb una especial predilecció per ambientacions tardorals, boiroses i capvesprals.

e.- Creiem, per acabar, que es poden donar molts qualificatius a la poesia de Carner, però no pas el d'immutable. Les teoritzacions de Riba, tornem-hi a insistir, només afecten l'etapa noucentista de Carner, que quallà en la modalitat arbitrària. La crítica ha tendit a exalçar el Carner virtuós, juganer, sovint intrascendent: "Cançoneta incerta», "Cançonetes del 'Déu-nos-do"», "Una fulla», les auques... La poesia al servei de l'orfebreria verbal i del joc. Del Carner de la postguerra s'han destacat sobretot els poemes civils i, a partir dels 70 , $N a b i$ ha començat a rebre l'atenció que es mereix. El resultat d'aquestes aproximacions parcials és que encara perdura una visió molt limitada, si més no descompensada, de l'obra del més gran dels nostres poetes, una obra caracteritzada precisament per la seva gran diversitat, per la seva força desbordant, per la virtut essencial del prodigiós desplegament de formes, temes, figuracions i tonalitats. 